\title{
Advances in Retinal Imaging and Applications in Diabetic Retinopathy Screening: A Review
}

Beau J. Fenner - Raymond L. M. Wong - Wai-Ching Lam •

Gavin S. W. Tan · Gemmy C. M. Cheung

Received: June 12, 2018 / Published online: November 10, 2018

(C) The Author(s) 2018

\section{ABSTRACT}

Rising prevalence of diabetes worldwide has necessitated the implementation of populationbased diabetic retinopathy (DR) screening

Enhanced Digital Features To view enhanced digital features for this article go to https://doi.org/10.6084/ m9.figshare.7253039.

B. J. Fenner

Residency Program, Singapore National Eye Centre, Singapore, Singapore

R. L. M. Wong

Department of Ophthalmology and Visual Sciences, The Chinese University of Hong Kong, Hong Kong, China

W.-C. Lam

Department of Ophthalmology, The University of Hong Kong, Shatin, Hong Kong

\section{G. S. W. Tan}

Surgical Retina Department, Singapore National Eye Centre, Singapore, Singapore

G. S. W. Tan · G. C. M. Cheung

Ophthlamology and Visual Sciences Academic

Clinical Program, Duke-NUS Graduate Medical

School, Singapore, Singapore

G. S. W. Tan · G. C. M. Cheung ( $\varangle)$

Retina Research Group, Singapore Eye Research Institute, Singapore, Singapore

e-mail: gemmy.cheung.c.m@singhealth.com.sg

G. C. M. Cheung

Medical Retina Department, Singapore National Eye Centre, Singapore, Singapore programs that can perform retinal imaging and interpretation for extremely large patient cohorts in a rapid and sensitive manner while minimizing inappropriate referrals to retina specialists. While most current screening programs employ mydriatic or nonmydriatic color fundus photography and trained image graders to identify referable DR, new imaging modalities offer significant improvements in diagnostic accuracy, throughput, and affordability. Smartphone-based fundus photography, macular optical coherence tomography, ultrawidefield imaging, and artificial intelligence-based image reading address limitations of current approaches and will likely become necessary as DR becomes more prevalent. Here we review current trends in imaging for DR screening and emerging technologies that show potential for improving upon current screening approaches.

Keywords: Artificial intelligence; Deep learning; Diabetic retinopathy; Optical coherence tomography; Retina; Ultrawide field imaging

\section{DIABETIC RETINOPATHY SCREENING PROGRAMS IN MODERN OPHTHALMIC PRACTICE}

Over the past few decades, the global prevalence of diabetes in adults has nearly doubled, 
increasing from $4.7 \%$ in 1980 to $8.5 \%$ in 2014 , with rapid increases in middle- and low-income countries [1]. The World Health Organization projects that diabetes will be the seventh leading cause of death worldwide by 2030 [1]. Among diabetic complications, the prevalence of diabetic retinopathy (DR), diabetic macular edema (DME), and proliferative diabetic retinopathy (PDR) among individuals with diabetes is approximately $35 \%, 7 \%$, and $3-7 \%$, respectively [2-4].

Diabetic eye disease is a prime candidate for a universal screening program. It is one of the most common causes of legal blindness in developed countries, with DME and PDR being the two major vision-threatening complications of diabetes $[5,6]$. Treatment before the onset of advanced DR is highly effective in preventing visual loss [7, 8]. However, patients often remain asymptomatic and do not present until advanced complications such as vitreous hemorrhage or retinal detachment develop, by which time treatment outcomes are less favorable and often incur high costs $[9,10]$. A universal screening program for DR aims to identify high-risk individuals and instigate treatment before complications develop [11, 12].

The first diabetic retinopathy screening programs were implemented during the 1980s and early 1990s [13-15]. These early programs were tremendously successful in reducing the incidence of DR-related blindness. In Stockholm early DR screening efforts decreased specialist referrals for DR-related blindness by an average of $47 \%$ per year over a 5 -year period following the introduction of DR screening in 1991 [14]. Implementation of DR screening in the UK had similarly impressive results, with a $49 \%$ reduction in DR-related blindness in Wales during the 2007-2015 period that was attributed to DR screening programs [16].

\section{RETINAL PHOTOGRAPHY FOR DIABETIC RETINOPATHY SCREENING}

Currently, the International Council of Ophthalmology (ICO) guidelines for DR screening include retinal examination with either (1) direct or indirect ophthalmoscopy or slit-lamp biomicroscopy or (2) mydriatic or nonmydriatic fundus imaging with $\geq 30^{\circ}$ mono- or stereophotography, with or without OCT. Retinal imaging review should be by an examiner sufficiently well trained to assess DR severity [17]. The level of DR classification afforded by screening programs is stipulated by the American Teleophthalmology Associations (ATA; Table 1), with category 1 providing a level of detail useful for population screening.

Fundus photography for DR screening has become widely adopted worldwide as the availability of imaging platforms increases $[18,19]$. Although binocular slit-lamp ophthalmoscopy has remained a standard against which other DR screening approaches are judged, fundus photography is more cost-effective and does not require ophthalmologist consultation [20-23]. With training and adequate retinal image quality, graders can differentiate eyes with different severities of DR and identify eyes with PDR that require urgent referral for treatment. Meta-analysis of 20 studies with 1,960 participants yielded a combined sensitivity for DR screening programs of $80 \%$ in detecting no DR or PDR, more than $70 \%$ for detecting mild or moderate nonproliferate diabetic retinopathy (NPDR) and clinically significant macular edema (CSME), and 53\% in detecting severe NPDR [24]. The specificity of screening programs was typically $>90 \%$ in the same study.

Improvements in fundus photography, particularly since the 1970s, have resulted in increased photographic quality and throughput that has facilitated implementation of teleophthalmology programs. Digital cameras are now approaching the potential resolution of film cameras, and digital photography is considered a reliable alternative to traditional film-based seven-field photography used in the Early Treatment of Diabetic Retinopathy Study (ETDRS) $[25,26]$. Current fundus cameras have resolutions in the 20 megapixel range (e.g., Canon CR-2), which exceeds the 2-3 megapixel resolution required to display a single microaneurysm at the minimum identifiable diameter of 2-3 pixels [27]. Incorporation of image sensors in the range of 64 megapixels, however, is 
Table 1 Validation levels of diabetic retinopathy used by the ATA. Adapted from Tozer et al. [84] and Li et al. [85]

\begin{tabular}{|c|c|c|c|c|}
\hline & \multicolumn{4}{|c|}{ ATA clinical validation categories } \\
\hline & Category 1 & Category 2 & Category 3 & Category 4 \\
\hline $\begin{array}{l}\text { Disease } \\
\text { characterization }\end{array}$ & $\begin{array}{l}\text { No or minimal DR } \\
\text { Worse than } \\
\text { minimal DR }\end{array}$ & $\begin{array}{l}\text { DME present } \\
\text { Severe or worse NPDR, } \\
\text { or PDR }\end{array}$ & $\begin{array}{l}\text { Mild, moderate, or severe } \\
\text { NPDR } \\
\text { Early or high-risk PDR } \\
\text { DME } \\
\text { Matches clinical examination } \\
\text { by dilated fundoscopy }\end{array}$ & $\begin{array}{l}\text { Exceeds ETDRS } \\
\text { photos to } \\
\text { determine DR and } \\
\text { DME level }\end{array}$ \\
\hline Clinical value & Screening only & $\begin{array}{l}\text { Screening and risk } \\
\text { stratification }\end{array}$ & $\begin{array}{l}\text { Screening, risk stratification, } \\
\text { and treatment } \\
\text { recommendations }\end{array}$ & $\begin{array}{l}\text { Replaces ETDRS } \\
\text { photos in clinical } \\
\text { or research settings }\end{array}$ \\
\hline Current programs & $\begin{array}{l}\text { OPHDIAT } \\
\text { (France), EyePacs } \\
\text { (USA), Digiscope } \\
\text { (USA) }\end{array}$ & $\begin{array}{l}\text { EyeCheck (Netherlands), } \\
\text { NHS Diabetic Eye } \\
\text { Screening Program } \\
\text { (UK) }\end{array}$ & $\begin{array}{l}\text { Joslin Vision Network (US), } \\
\text { SiDRP (Singapore), } \\
\text { University of Alberta } \\
\text { (Canada) }\end{array}$ & None \\
\hline
\end{tabular}

required to achieve sharp focus everywhere for $45^{\circ}$ field diameter images using standard flash photography red-green-blue (RGB) image sensors $[28,29]$. At present, such cameras remain prohibitively expensive for many government screening programs.

\section{Mydriatic and Nonmydriatic Fundus Photography}

In terms of pupil dilation, there is no international consensus on the optimal approach to DR screening. Comparative trials of mydriatic and nonmydriatic fundus photography have demonstrated that mydriasis significantly reduces the proportion of ungradable photographs, from $19-26 \%$ to $4-5 \%$, and improves both the sensitivity (77-86\% vs. $81-94 \%)$ and specificity (77-95\% vs. 86-98\%) of DR detection compared with undilated photography [24, 30-32]. Despite this, for patient convenience and logistical reasons, many programs employ nonmydriatic photography, with mydriasis being reserved for cases where ungradable images are obtained (Table 2).

\section{Single and Multiple Field Fundus Photography}

Diabetic retinopathy severity grading, as established by the ETDRS with the modified Airlie House classification, requires a laborious process of capturing stereoscopic photos of seven standardized $30^{\circ}$ fundus fields encompassing a horizontal fundus viewing angle of $75^{\circ}$. Photos are then mounted in plastic sheets and viewed against light boards using stereo viewers at $5 \times$ magnification [33]. While this approach remains the gold standard for photographic diagnosis and grading of DR, it is clearly inappropriate for large-scale population screening [34]. Dilated single-field $45^{\circ}$ fundus photography has a sensitivity of $76-84 \%$ and specificity of $82-92 \%$ for DR [32]. In the UK, nonmydriatic fundus cameras are used for mydriatic photography with two $45^{\circ}$ fields (one fovea centered and one disc centered) [35]. Most other programs employ single $45^{\circ}$ field fundus photos or two- and three-field photography for screening purposes (Table 2). 
Table 2 Diabetic retinopathy screening programs for different ATA diabetic retinopathy characterization levels. Adapted from Tozer et al. [84]

\begin{tabular}{|c|c|c|c|c|c|c|}
\hline & Examiner & Imaging platform & Photos & Dilation & $\begin{array}{l}\text { Grading } \\
\text { system }\end{array}$ & References \\
\hline \multicolumn{7}{|l|}{ ATA category 1} \\
\hline DigiScope (USA) & $\begin{array}{l}\text { Nurses or non- } \\
\text { medical staff }\end{array}$ & Digiscope & $\begin{array}{l}10 \text { Non- } \\
\text { stereo, } 55^{\circ}\end{array}$ & Yes & ETDRS & {$[86]$} \\
\hline EyePACS (USA) & $\begin{array}{l}\text { Nurses or non- } \\
\text { medical staff }\end{array}$ & $\begin{array}{l}\text { Canon CR-DGI and } \\
\text { Canon CR-1 }\end{array}$ & $\begin{array}{l}3 \text { Non-stereo, } \\
45^{\circ}\end{array}$ & $\begin{array}{l}\text { As } \\
\text { needed }\end{array}$ & ETDRS & {$[87]$} \\
\hline Ophdiat (France) & Nurses & $\begin{array}{l}\text { Canon CR-DGI and } \\
\text { Topcon NW6 }\end{array}$ & 2 Non-stereo & $\begin{array}{l}\text { As } \\
\text { needed }\end{array}$ & ALFEDIAM & {$[88,89]$} \\
\hline \multicolumn{7}{|l|}{ ATA category 2} \\
\hline $\begin{array}{l}\text { EyeCheck (The } \\
\text { Netherlands) }\end{array}$ & $\begin{array}{l}\text { Nurses or non- } \\
\text { medical staff }\end{array}$ & $\begin{array}{c}\text { Canon CR5-45NM, } \\
\text { Topcon NW } 100\end{array}$ & 2 Non-stereo & $\begin{array}{l}\text { As } \\
\text { needed }\end{array}$ & ETDRS & {$[90]$} \\
\hline ENSP (UK) & Non-medical staff & Multiple platforms & 2 Stereo & $\begin{array}{l}\text { As } \\
\text { needed }\end{array}$ & NDESP & {$[91]$} \\
\hline \multicolumn{7}{|l|}{ ATA category 3} \\
\hline $\begin{array}{l}\text { RAMP (Hong } \\
\text { Kong) }\end{array}$ & Non-medical staff & Multiple platforms & 2 Non-stereo & Yes & ETDRS & {$[10]$} \\
\hline JVN (US) & Non-medical staff & $\begin{array}{l}\text { Topcon TRC } \\
\text { NW6S }\end{array}$ & 3 Stereo & No & ETDRS & {$[92,93]$} \\
\hline SiDRP (Singapore) & Non-medical staff & Topcon TRC-NW6 & 1 Non-stereo & No & ETDRS & {$[40,94]$} \\
\hline $\begin{array}{l}\text { University of } \\
\text { Alberta (Canada) }\end{array}$ & Non-medical staff & Multiple platforms & $\begin{array}{l}2 \text { Stereo, } 5 \\
\text { non-stereo }\end{array}$ & Yes & ETDRS & {$[95,96]$} \\
\hline
\end{tabular}

\section{Optical Coherence Tomography for Diabetic Macular Edema Screening}

Although many current screening programs are efficient in detecting referable DR, the accurate diagnosis of DME is more challenging. An especially problematic aspect of two-dimensional fundus photography for DME detection is the inability to reliably identify retinal thickening. The English National Screening Program (ENSP) for DR employs three photographic markers, namely (1) exudates within one disc diameter of the fovea, (2) circinates within the macula, and (3) microaneurysms or hemorrhages within one disc diameter of the fovea associated with best corrected visual acuity of worse than $6 / 12$, as surrogates for DME [35]. This approach, while reasonable within the limits of currently used imaging platforms, has limited diagnostic accuracy. Only $17 \%$ of patients with hemorrhages or microaneurysms within one disc diameter of the fovea and reduced visual acuity had thickening on macular OCT, while only $6 \%$ had macular edema. Similarly, only $27 \%$ of those with macular exudates within one disc diameter of the fovea or circinates within two disc diameters of the fovea had thickening on 
macular OCT [36]. A cross-sectional observational study from Hong Kong recorded a falsepositive rate of $86.6 \%$ for macular edema using conventional fundus photography screening methods [37]. Among eyes proven to have macular edema on OCT, approximately one quarter to one-third are missed by fundus photography screening [38].

Several studies have investigated the incorporation of macular OCT as part of a DR screening program to determine if this approach is beneficial from a medical and costeffectiveness perspective. Prescott et al. found that use of OCT in cases where color fundus photos suggested the presence of macular edema resulted in direct cost savings of $16-17 \%$ because of fewer unnecessary referrals without a measurable decrease in medical benefits [19]. A cost-effectiveness study of DME screening in Hong Kong found that although the screening cost per patient increased by $35 \%$ if OCT was performed on all patients undergoing color fundus photography, the cost per quality-adjusted life-year was reduced by $45 \%$ (RW, unpublished). In contrast to these promising studies, more recent work from Australia that compared DR screening using a standard color fundus photography (CentreVue DRS fundus camera, Padova) with a combined fundus camera and OCT instrument (3D OCT1 Maestro, Topcon, Tokyo) concluded that there was no added benefit of OCT [39]. This was due to the substantial increase in ungradable fundus photos obtained with the combined fundus camera/OCT scanner that required specialist referral, negating the benefit of reduced referrals for macular edema based on OCT imaging. This negative result, however, was largely specific to the scanning instrument chosen and would likely have been overcome with the use of a dedicated fundus camera and OCT scanner setup. That said, significant challenges remain to the addition of dedicated macular OCT scans to current DR screening protocols, such as the relatively low availability of OCT machines and expertise of operators in general outpatient clinics for screening due to cost constraints.

\section{GRADING FUNDUS PHOTOS FOR SIGNS OF DIABETIC RETINOPATHY}

\section{Telemedicine Standards for DR Screening}

The degree to which DR severity and thus referral and treatment urgency is assessed varies has been categorized into four levels by the ATA. Category 1 includes programs that can distinguish no or minimal DR from more than minimal DR, while category 4 enables complete categorization of DR into mild, moderate, and severe nonproliferative disease, early and highrisk proliferative disease, and whether macular edema is present (Table 2). Current DR screening programs employ ATA categories 1-3 (Table 2); as a result, the incidence of DR and DR-related blindness have fallen dramatically [35]. In tandem, the implementation of telemedicine DR screening programs is cost-effective compared with physician-based DR screening approaches and generates similar health outcomes [40].

\section{Automated DR Image Assessment Systems}

A relative scarcity of ophthalmologists necessitates the use of specially trained non-ophthalmologist and non-physician graders for DR screening. Such graders are used in most developed countries nowadays (Table 2), and previous work has demonstrated that this approach is adequate for DR detection [41-44]. Despite this, the growing prevalence of diabetes has placed greater pressure on healthcare systems to increase screening throughput while minimizing costs. Automated grading for diabetic retinopathy was reported in the 1990s, when Gardner and colleagues described the use of an artificial neural network capable of detecting diabetic retinopathy with $88 \%$ sensitivity and $83 \%$ specificity relative to an ophthalmologist [45]. Their system and others like it employed pattern recognition algorithms trained to identify specific retinopathy features, such as microaneurysms, and as such required time- 
consuming pre-processing of training images to isolate clinically important features and develop mathematical descriptors of different lesion types.

Deep Learning (DL) is a new iteration of artificial intelligence (AI) that employs convolutional neural networks (CNNs) to interpret images by repititive analysis and comparison of the output with a standard (i.e., a human grader) and self-correcting if an error is made. DL is made possible by recent advances in software programming, the availability of large data sets used to train image recognition software, and high-resolution digital imaging systems [46-50]. Multiple studies have shown successful results in developing DL algorithms that are capable of identifying referable DR without the prior need to teach the computer systems specific features of DR. The sensitivities and specificities of these approaches are in general $>$ $90 \%$ and $95 \%$, respectively [44, 47-49]. Importantly, the negative predictive value of current DL algorithms for DR detection is now upwards of $99 \%$, with less than $1 \%$ probability of missing severe NPDR, PDR, or macular edema [51]. Current generation DL algorithms that employ standard color fundus photos have already achieved grading performance similar to retinal specialists [52, 53]. A large-scale trial of a DL algorithm trained for DR screening with a multi-ethnic data set also included additional algorithms for detection of glaucoma and agerelated macular generation (AMD) [48]. Detection of possible glaucoma had a sensitivity of 96.4\% (95\% CI 81.7-99.9\%) and specificity was $87.2 \%$ (95\% CI 86.8-87.5\%), while detection of possible AMD achieved a sensitivity of $93.2 \%$ (95\% CI $91.1-99.8 \%$ ) and specificity of $88.7 \%$ (95\% CI 88.3-89.0\%). More recently, DL approaches were even used for automated interpretation of macular OCT scans and demonstrated diagnostic accuracy exceeding that of trained ophthalmologists for a variety of macular diseases including DME [54].

Several DL algorithms for DR screening, including the recently FDA-approved IDx-DR algorithm [51, 55], have been reported. These can broadly be grouped into lesion-based disease detection systems and image-based ("black box") detection systems. Lesion-based systems are trained using known disease features of DR such as microaneurysms, blot hemorrhages, and exudates. In contrast, black box disease detection systems, such as the Google Brain system [47], are trained using fundus photographs that have been graded for DR, but the specific pathologic features being detected by the algorithm remain unknown, and output is given simply as a positive or negative response to a disease state.

Clearly DL approaches hold great promise for rapid, reliable, and cost-effective screening for diabetic retinopathy. However, several important challenges remain that complicate the introduction of these algorithms into large-scale screening programs. Despite the impressive performance previously reported by the Google Brain team using an image-based DR detection system, recently presented work from Lynch et al. [56] revealed that this "black box" approach to DR screening is highly vulnerable to seemingly innocuous alterations of fundus images. Using a series of reference DR fundus photos containing typical features of DR, slight pixel modifications $(0.12-0.51 \%$ of total pixels) were introduced into the images that were essentially imperceptible to human readers and did not obviously alter the appearance of the DR lesions. These altered photos were then presented to an image-based CNN previously trained with half a million DR photos. The modified images were classified as normal by the image-based $\mathrm{CNN}$, while the lesion-based system still detected DR. In light of this work, the potential value of image-based CNNs in identifying novel fundus signs of DR needs to be balanced against their potential failure to detect clinically obvious disease.

Another limitation of many current DL approaches is the binary nature of algorithm development. Most contemporary CNNs are trained using normal fundus images and images with a single disease, such as DR. The variety of retinal pathologies and differences in referral urgency make this approach inappropriate in a typical heterogenous population that would attend retinal screening programs. A recent attempt to use contemporary CNNs trained with a variety of retinal pathologies, including DR, AMD, vein and artery occlusions, 
hypertensive retinopathy, Coats disease, and retinitis, found that diagnostic accuracy for any particular pathology dropped precipitously with each additional disease added to the diagnostic algorithm, to as low as $20-30 \%$ after the addition of ten distinct retinal pathologies [57]. It remains to be seen whether these limitations will be overcome with the development of more sophisticated DL algorithms and more powerful computer hardware. Additionally, the usefulness of algorithms trained using retinal images from a particular population may not extend to other populations [48]. While the clinical findings of DR are largely similar between races, it is possible that DL algorithms are also recognizing new DR markers that are not shared among different populations.

\section{EMERGING IMAGE MODALITIES FOR DR SCREENING}

\section{Ultrawide-Field Imaging for Diabetic Retinopathy Screening}

The narrow field of view in ordinary fundus photographs (e.g., single-field $45^{\circ}$ or even a 7-field standard ETDRS) may exclude peripheral DR lesions. This is significant when predominantly peripheral lesions (PPLs) are associated with retinal ischemia, DR progression, and development of proliferative retinopathy $[58,59]$. Eyes with PPLs were shown to have a 3.2-fold increased risk of two-step or more DR progression and a 4.7-fold increased risk for progression to proliferative disease [58]. Ultrawide-field (UWF) imaging, which can image $80 \%$ of the retinal surface, is therefore a potentially important imaging modality for DR screening. Use of UWF imaging for DR screening can achieve a sensitivity up to $99 \%$ and specificity up to $97 \%$ for DR [34]. The Optos (Daytona, Optos) and Clarus 500 (Carl Zeiss, Oberkochen) are currently available UWF imaging platforms that both enable $200^{\circ}$ field retinal imaging in only one or two images.

Optos is a scanning laser ophthalmoscope that produces retinal images of up to $200^{\circ}$ in non-mydriatic eyes $[60,61]$, representing more than three times the retinal surface of traditional ETDRS seven-field photos [62]. Such images enable identification of peripheral retinal lesions of diabetic retinopathy that cannot be seen on conventional fundus photos [60] (Fig. 1). The recently released Clarus 500 captures $133^{\circ}$ fundus photos or $200^{\circ}$ composited photos but, unlike Optos, is able to produce true-color images that may potentially enable more accurate identification of DR lesions, although this has yet to be demonstrated in clinical trials.

The rate of ungradable fundus photos, a common cause of specialist referral in DR screening programs, was dramatically reduced when nonmydriatic UWF was employed compared with conventional nonmydriatic multifield color fundus photography in a US-based DR teleophthalmology program involving over 25,000 patients [63]. An ungradable rate per patient for DR was $2.8 \%$ with Optos UWF compared with $26.9 \%$ with multifield photography, while the ungradable rate for DME was $3.8 \%$ with Optos UWF compared with $26.2 \%$ with multifield photography. Overall, the study demonstrated an $81 \%$ reduction in ungradable fundus photos and almost twofold increased DR detection.

At present, the major constraint to widespread adoption of UWF systems such as the Optos and Clarus for DR screening programs is largely financial-such instruments cost an order of magnitude more than conventional fundus camera setups. Despite the impressive

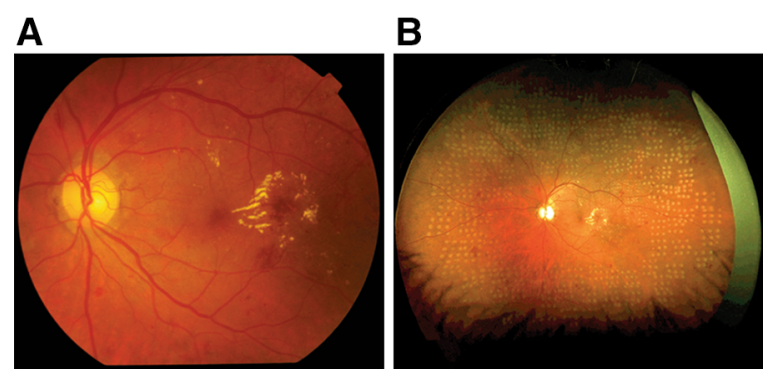

Fig. 1 Comparison of standard $45^{\circ}$ fundus photography and ultrawide-field imaging of diabetic retinopathy using the Optos imaging platform (Optos, Daytona, IL). a Diabetic retinopathy with macular edema, imaged using a $45^{\circ}$ field fundus camera; $\mathbf{b}$ the same eye following panretinal photocoagulation, imaged with the Optos ultrawidefield imaging platform 
outcomes of clinical trials, it remains unclear whether the cost savings of reduced inappropriate referrals are sufficient to justify the financial outlay [64].

\section{OCT Angiography as a Screening Tool}

OCT angiography (OCT-A) is a novel noninvasive imaging modality that can detect blood flow within the retina (Fig. 2). In diabetic retinopathy, microaneurysms and retinal neovascularization can be detected using OCT-A noninvasively [65]. Although the clinical utility of OCT-A remains to be established [66], several recent works have highlighted its potential for incorporation into DR screening approaches. Accurate noninvasive grading of DR severity by OCT-A analysis has been demonstrated via analyses of foveal avascular zone acircularity [67] and retinal plexus densitometry [68-70]. Automation of OCT-A image analysis has also been used for quantitative assessment of DR vascular changes that correlate with visual acuity and may be useful for monitoring DR progression [71].

A

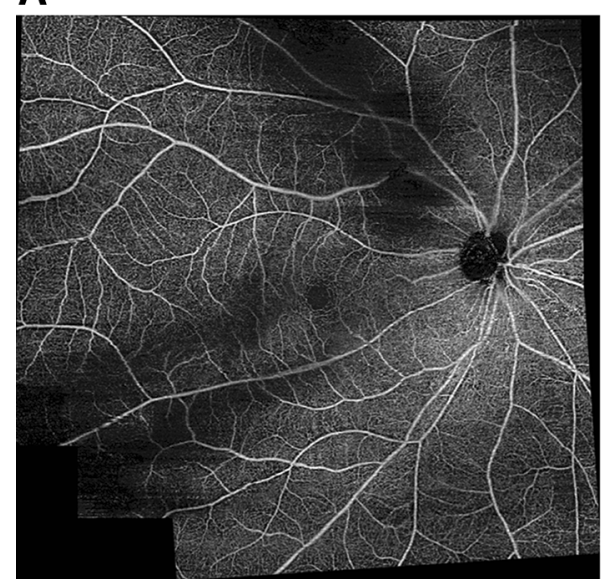

Fig. 2 Wide-field OCT angiograms of diabetic retinopathy using image montaging captured using the Plex Elite 9000 swept-source OCT angiography platform (Carl Zeiss AG, Oberkochen, Germany). Retinal swept-source OCTA slabs demonstrate mild non-proliferative diabetic

\section{Portable Fundus Photography for Detection of Diabetic Retinopathy}

Modern digital color fundus cameras, although widely available in developed regions, still typically cost many thousands of dollars, are large and cumbersome, and require specially trained ophthalmic photographers. This often limits their deployment in developing regions and in areas with underserved patient populations who are less likely to attend regular ophthalmic screening. In recent years, several manufacturers have attempted to address this problem by developing fundus photography attachments for smartphones with digital cameras. Modern smartphone cameras are capable of producing very high-quality digital images the match or exceed the resolution of dedicated clinicalgrade retinal cameras, albeit with smaller image sensors. Contemporary smart phones feature $\geq 10$ megapixel wide-angle and telephoto cameras with optical image stabilization and are a potentially useful alternative to conventional fundus cameras.

Fundus photography using a smartphone and handheld 20-diopter condensing lens has been successfully used to capture fundus photos

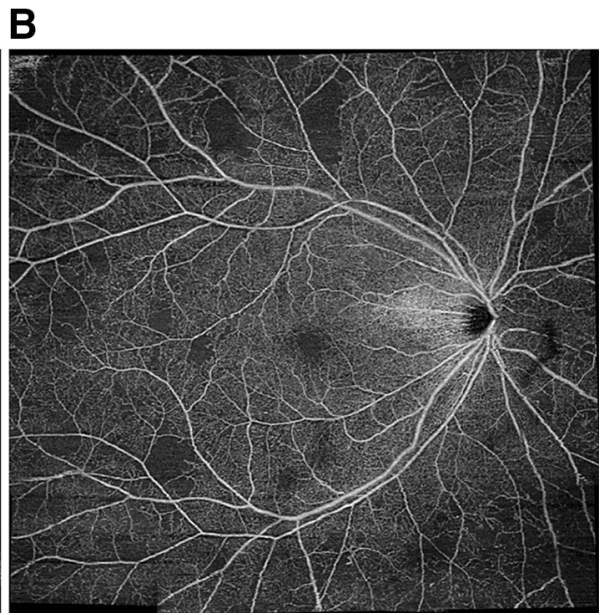

retinopathy with intact retinal vasculature (a) and moderate non-proliferative diabetic retinopathy and multiple foci of capillary fallout seen in the temporal macula and beyond the vascular arcades $(\mathbf{b})$ 
[72], and since then several commercial developers have released hardware attachments and software to enable convenient fundus photography. Current smartphone-based imaging solutions are based on the incorporation of additional lens elements in line with the smartphone camera and typically come with custom software that enables capture, labeling, and secure transmission of fundus photos. Outcomes of recent prospective clinical trials with smartphone-based fundus photography systems used for DR screening are summarized in Table 3. In most reports the sensitivity for DR using images captured from smartphones is comparable to slit-lamp biomicroscopy or dedicated fundus camera imaging with the benefit of far greater affordability.

Given the obvious benefits of low cost and portability, there is clearly excellent potential in smartphone-based DR screening, though the questionable ability of these imaging systems to provide fundus images through undilated pupils poses a problem for screening programs that do not employ routine dilation. Concerns about acute angle closure precipitated by dilation, particularly in East Asian populations [73], may render this approach undesirable in certain regions. Portable nonmydriatic fundus cameras are widely available and have been successfully tested for DR screening (Table 3), with diagnostic performance comparable to smartphonebased systems. These devices offer somewhat better diagnostic performance than fixed fundus cameras in terms of image gradeability and diagnostic accuracy, but the benefit of portability cannot be overstated [74-77]. Several large trials have demonstrated the potential of these devices for detecting referable DR in developing regions [78-81]. It is likely that the incorporation of both smartphone-based and dedicated

Table 3 Outcomes of clinical studies using portable retinal cameras for diabetic retinopathy screening

\begin{tabular}{|c|c|c|c|c|c|c|}
\hline \multirow[t]{2}{*}{ Study } & \multirow[t]{2}{*}{ Camera } & \multirow{2}{*}{$\begin{array}{l}\text { Ungradeable } \\
\text { images }\end{array}$} & \multirow[t]{2}{*}{ Mydriasis } & \multicolumn{2}{|c|}{ Detection of DR } & \multirow{2}{*}{$\begin{array}{l}\text { Standard for } \\
\text { comparison }\end{array}$} \\
\hline & & & & $\begin{array}{l}\text { Sensitivity } \\
(\%)\end{array}$ & $\begin{array}{l}\text { Specificity } \\
(\%)\end{array}$ & \\
\hline \multicolumn{7}{|c|}{ Smartphone-based fundus cameras } \\
\hline $\begin{array}{l}\text { Russo et al. } \\
{[76]}\end{array}$ & D-Eye (D-Eyecare) & $3.75 \%$ & Yes & $75-89$ & $93-100$ & $\begin{array}{c}\text { Dilated fundus } \\
\text { examination }\end{array}$ \\
\hline $\begin{array}{l}\text { Toy et al. } \\
{[74]}\end{array}$ & $\begin{array}{l}\text { Paxos Scope (Verana } \\
\text { Health) }\end{array}$ & $2 \%$ & Yes & 91 & 99 & $\begin{array}{l}\text { Dilated fundus } \\
\text { examination }\end{array}$ \\
\hline $\begin{array}{l}\text { Ryan et al. } \\
{[75]}\end{array}$ & $\begin{array}{l}\text { Unmodified smartphone } \\
\text { with hand-held 20D lens }\end{array}$ & $1.8 \%$ & Yes & 50 & 94 & $\begin{array}{l}\text { 7-field ETDRS } \\
\text { fundus photos }\end{array}$ \\
\hline $\begin{array}{l}\text { Rajalakshmi } \\
\text { et al. [77] }\end{array}$ & $\begin{array}{l}\text { Fundus-on-phone (FOP, } \\
\text { Remidio Innovative } \\
\text { Solutions) }\end{array}$ & None & Yes & 92.7 & 98.4 & $\begin{array}{l}\text { Zeiss FF450 Plus } \\
\text { digital fundus } \\
\text { camera }\end{array}$ \\
\hline \multicolumn{7}{|c|}{ Dedicated portable nonmydriatic fundus cameras } \\
\hline $\begin{array}{l}\text { Ting et al. } \\
{[97]}\end{array}$ & Eyescan (OIS) & $8.5 \%$ & Yes & 93 & 98.2 & $\begin{array}{l}\text { Dilated fundus } \\
\text { examination }\end{array}$ \\
\hline $\begin{array}{l}\text { Zhang et al. } \\
{[98]}\end{array}$ & $\begin{array}{l}\text { Pictor Smartscope (Volk } \\
\text { Optical) }\end{array}$ & $6-14 \%$ & No & $64-88$ & $72-84$ & $\begin{array}{l}\text { Dilated fundus } \\
\text { examination }\end{array}$ \\
\hline $\begin{array}{l}\text { Sengupta } \\
\text { et al. [79] }\end{array}$ & $\begin{array}{l}\text { Pictor Smartscope (Volk } \\
\text { optical) }\end{array}$ & - & No & $88-93$ & $84-90$ & $\begin{array}{c}\text { Dilated fundus } \\
\text { examination }\end{array}$ \\
\hline
\end{tabular}


portable fundus cameras into DR screening programs will increase dramatically in the coming years, particular in developing countries with large rural areas where clinic review in often not feasible. Recent incorporation of AIbased automatic image grading to smartphone fundus images [82] offers potential for even further improvements to the cost-effectiveness and convenience of screening programs.

\section{CONCLUSION}

Over the past few decades, diabetic retinopathy screening programs have been implemented in essentially all developed nations and many developing nations $[10,83]$. While most current screening programs employ conventional fundus photography with trained grading staff, research over the past few years has demonstrated a role for newer imaging modalities and image analysis software that has the potential to improve screening accuracy and reduce the financial burden of these increasingly expensive programs. With the dramatic increase in diabetes prevalence currently occurring worldwide, it is clear that more efficient screening programs will be required not only to ensure early detection of disease, but also to reduce inappropriate referrals to ophthalmologists for non-sightthreatening disease that is more appropriately managed with continued observation in a primary healthcare setting.

This article is based on previously conducted studies and does not contain any studies with human participants or animals performed by any of the authors.

\section{ACKNOWLEDGEMENTS}

Funding. No funding or sponsorship was received for this study or publication of this article.

Authorship. All named authors meet the international Committee of Medical Journal Editors (ICMJE) criteria for authorship for this article, take responsibility for the integrity of the work, and have given their approval for this version to be published.

Disclosures. B.J. Fenner, R.L.M. Wong, and G.S.W. Tan do not have any personal, financial, commercial, or academic conflicts of interest. W.C. Lam is a consultant for Novartis and Bayer. G.C.M. Cheung is a consultant for Topcon, Novartis, Bayer, Allergan, Roche, Boehringher-Ingelheim, and Samsung.

Compliance with Ethics Guidelines. This article is based on previously conducted studies and does not contain any studies with human participants or animals performed by any of the authors.

Open Access. This article is distributed under the terms of the Creative Commons Attribution-NonCommercial 4.0 International License (http://creativecommons.org/licenses/ by-nc/4.0/), which permits any noncommercial use, distribution, and reproduction in any medium, provided you give appropriate credit to the original author(s) and the source, provide a link to the Creative Commons license, and indicate if changes were made.

\section{REFERENCES}

1. Cho NH, et al. IDF diabetes atlas. 7th ed. Brussels: International Diabetes Federation; 2015.

2. Yau JW, et al. Global prevalence and major risk factors of diabetic retinopathy. Diabetes Care. 2012;35(3):556-64.

3. Varma $\mathrm{R}$, et al. Prevalence of and risk factors for diabetic macular edema in the United States. JAMA Ophthalmol. 2014;132(11):1334-40.

4. Lee R, Wong TY, Sabanayagam C. Epidemiology of diabetic retinopathy, diabetic macular edema and related vision loss. Eye Vis (Lond). 2015;2:17.

5. Cheung N, Mitchell P, Wong TY. Diabetic retinopathy. Lancet. 2010;376(9735):124-36.

6. Aiello LP, et al. Diabetic retinopathy. Diabetes Care. 1998;21(1):143-56.

7. Group TDRSR. Photocoagulation treatment of proliferative diabetic retinopathy. Clinical application 
of Diabetic Retinopathy Study (DRS) findings, DRS Report Number 8. The Diabetic Retinopathy Study Research Group. Ophthalmology. 1981;88(7):583-600.

8. Group TDRSR. Early photocoagulation for diabetic retinopathy. ETDRS report number 9. Early Treatment Diabetic Retinopathy Study Research Group. Ophthalmology. 1991;98(5 Suppl):766-85.

9. Ross EL, et al. Cost-effectiveness of aflibercept, bevacizumab, and ranibizumab for diabetic macular edema treatment: analysis from the Diabetic Retinopathy Clinical Research Network Comparative Effectiveness Trial. JAMA Ophthalmol. 2016;134(8):888-96.

10. Gangwani RA, et al. Diabetic retinopathy screening: global and local perspective. Hong Kong Med J. 2016;22(5):486-95.

11. Stefansson E, et al. Screening and prevention of diabetic blindness. Acta Ophthalmol Scand. 2000;78(4):374-85.

12. Tung $\mathrm{TH}$, et al. Economic evaluation of screening for diabetic retinopathy among Chinese type 2 diabetics: a community-based study in Kinmen, Taiwan. J Epidemiol. 2008;18(5):225-33.

13. Lau HC, et al. Mass screening for diabetic retinopathy - a report on diabetic retinal screening in primary care clinics in Singapore. Singap Med J. 1995;36(5):510-3.

14. Backlund LB, Algvere PV, Rosenqvist U. New blindness in diabetes reduced by more than onethird in Stockholm County. Diabet Med. 1997;14(9):732-40.

15. Newcomb PA, Klein R. Factors associated with compliance following diabetic eye screening. J Diabet Complicat. 1990;4(1):8-14.

16. Thomas RL, et al. Retrospective analysis of newly recorded certifications of visual impairment due to diabetic retinopathy in Wales during 2007-2015. BMJ Open. 2017;7(7):e015024.

17. Wong TY, et al. Guidelines on diabetic eye care: the international council of ophthalmology recommendations for screening, follow-up, referral, and treatment based on resource settings. Ophthalmology. 2018;125(10):1608-22.

18. Lian JX, et al. Systematic screening for diabetic retinopathy (DR) in Hong Kong: prevalence of DR and visual impairment among diabetic population. Br J Ophthalmol. 2016;100(2):151-5.

19. Prescott $\mathrm{G}$, et al. Improving the cost-effectiveness of photographic screening for diabetic macular oedema: a prospective, multi-centre, UK study. Br J Ophthalmol. 2014;98(8):1042-9.

20. Scotland GS, et al. Cost-effectiveness of implementing automated grading within the national screening programme for diabetic retinopathy in Scotland. Br J Ophthalmol. 2007;91(11):1518-23.

21. Kawasaki R, et al. Cost-utility analysis of screening for diabetic retinopathy in Japan: a probabilistic Markov modeling study. Ophthalmic Epidemiol. 2015;22(1):4-12.

22. Rachapelle $S$, et al. The cost-utility of telemedicine to screen for diabetic retinopathy in India. Ophthalmology. 2013;120(3):566-73.

23. Lin DY, et al. The sensitivity and specificity of singlefield nonmydriatic monochromatic digital fundus photography with remote image interpretation for diabetic retinopathy screening: a comparison with ophthalmoscopy and standardized mydriatic color photography. Am J Ophthalmol. 2002;134(2):204-13.

24. Shi L, et al. Telemedicine for detecting diabetic retinopathy: a systematic review and meta-analysis. Br J Ophthalmol. 2015;99(6):823-31.

25. Bernardes R, Serranho P, Lobo C. Digital ocular fundus imaging: a review. Ophthalmologica. 2011;226(4):161-81.

26. Li HK, et al. Digital versus film Fundus photography for research grading of diabetic retinopathy severity. Investig Ophthalmol Vis Sci. 2010;51(11): 5846-52.

27. Taylor DJ, et al. Image-quality standardization for diabetic retinopathy screening. Expert Rev Ophthalmol. 2009;4(5):469-76.

28. Cornsweet T. Pixels in fundus cameras: how many do you need? Int Agency Prev Blindness. 2015(April 3):1-5.

29. Tyler ME, et al. Characteristics of digital fundus camera system affecting tonal resolution in color retinal images. J Ophthalmic Photo. 2009;31:9-14.

30. Scanlon $\mathrm{PH}$, et al. Comparison of two reference standards in validating two field mydriatic digital photography as a method of screening for diabetic retinopathy. Br J Ophthalmol. 2003;87(10):1258-63.

31. Scanlon $\mathrm{PH}$, et al. The effectiveness of screening for diabetic retinopathy by digital imaging photography and technician ophthalmoscopy. Diabet Med. 2003;20(6):467-74.

32. Murgatroyd $\mathrm{H}$, et al. Effect of mydriasis and different field strategies on digital image screening of 
diabetic eye disease. $\mathrm{Br} \quad \mathrm{J}$ Ophthalmol. 2004;88(7):920-4.

33. Group ETDRSR. Grading diabetic retinopathy from stereoscopic color fundus photographs-an extension of the modified Airlie House classification. ETDRS report number 10. Early Treatment Diabetic Retinopathy Study Research Group. Ophthalmology. 1991;98(5 Suppl):786-806.

34. Zimmer-Galler IE, Zeimer R. Telemedicine in diabetic retinopathy screening. Int Ophthalmol Clin. 2009;49(2):75-86.

35. Scanlon PH. The English National Screening Programme for diabetic retinopathy 2003-2016. Acta Diabetol. 2017;54(6):515-25.

36. Wharton H, Gibson J, Dodson P. How accurate are photographic surrogate markers used to detect macular oedema in the English National Screening Programme? In: Royal College of Ophthalmologists Annual Congress. Birmingham: Royal College of Ophthalmologists; 2011. p. 105.

37. Wong RL, et al. Are we making good use of our public resources? The false-positive rate of screening by fundus photography for diabetic macular oedema. Hong Kong Med J. 2017;23(4):356-64.

38. Wang YT, et al. Comparison of prevalence of diabetic macular edema based on monocular fundus photography vs optical coherence tomography. JAMA Ophthalmol. 2016;134(2):222-8.

39. O'Halloran RA, Turner AW. Evaluating the impact of optical coherence tomography in diabetic retinopathy screening for an aboriginal population. Clin Exp Ophthalmol. 2018;46(2):116-21.

40. Nguyen HV, et al. Cost-effectiveness of a National Telemedicine Diabetic Retinopathy Screening Program in Singapore. Ophthalmology. 2016;123(12):2571-80.

41. Bhargava M, et al. Accuracy of diabetic retinopathy screening by trained non-physician graders using non-mydriatic fundus camera. Singap Med J. 2012;53(11):715-9.

42. McKenna M, et al. Accuracy of trained rural ophthalmologists versus non-medical image graders in the diagnosis of diabetic retinopathy in rural China. Br J Ophthalmol. 2018;102:1471-6.

43. Deb N, et al. Screening for diabetic retinopathy in France. Diabetes Metab. 2004;30(2):140-5.

44. Owens DR, et al. Screening for diabetic retinopathy. Diabet Med. 1991;8:S4-10.
45. Gardner GG, et al. Automatic detection of diabetic retinopathy using an artificial neural network: a screening tool. Br J Ophthalmol. 1996;80(11):940-4.

46. Esteva A, et al. Dermatologist-level classification of skin cancer with deep neural networks. Nature. 2017;542(7639):115-8.

47. Gulshan V, et al. Development and validation of a deep learning algorithm for detection of diabetic retinopathy in retinal fundus photographs. JAMA. 2016;316(22):2402-10.

48. Ting DSW, et al. Development and validation of a deep learning system for diabetic retinopathy and related eye diseases using retinal images from multiethnic populations with diabetes. JAMA. 2017;318(22):2211-23.

49. Gargeya R, Leng T. Automated identification of diabetic retinopathy using deep learning. Ophthalmology. 2017;124(7):962-9.

50. Li Z, et al. Efficacy of a deep learning system for detecting glaucomatous optic neuropathy based on color fundus photographs. Ophthalmology. 2018;125(8):1199-1206.

51. Abramoff MD, et al. Improved automated detection of diabetic retinopathy on a publicly available dataset through integration of deep learning. Investig Ophthalmol Vis Sci. 2016;57(13):5200-6.

52. Krause J, et al. Grader variability and the importance of reference standards for evaluating machine learning models for diabetic retinopathy. Ophthalmology. 2018;125(8):1264-72.

53. Saha SK, et al. Automated quality assessment of colour fundus images for diabetic retinopathy screening in telemedicine. J Digit Imaging. 2018. https://doi.org/10.1007/s10278-018-0084-9.

54. De Fauw J, et al. Clinically applicable deep learning for diagnosis and referral in retinal disease. Nat Med. 2018;24:1342-50.

55. van der Heijden AA, et al. Validation of automated screening for referable diabetic retinopathy with the IDx-DR device in the Hoorn Diabetes Care System. Acta Ophthalmol. 2018;96(1):63-8.

56. Lynch SK, et al. Catastrophic failure in image-based convolutional neural network algorithms for detecting diabetic retinopathy. Investig Ophthalmol Vis Sci. 2017;58:3776.

57. Choi JY, et al. Multi-categorical deep learning neural network to classify retinal images: a pilot study employing small database. PLoS One. 2017;12(11):e0187336. 
58. Silva PS, et al. Peripheral lesions identified on ultrawide field imaging predict increased risk of diabetic retinopathy progression over 4 years. Ophthalmology. 2015;122(5):949-56.

59. Silva PS, et al. Diabetic retinopathy severity and peripheral lesions are associated with nonperfusion on ultrawide field angiography. Ophthalmology. 2015;122(12):2465-72.

60. Silva PS, et al. Nonmydriatic ultrawide field retinal imaging compared with dilated standard 7-field 35-mm photography and retinal specialist examination for evaluation of diabetic retinopathy. Am J Ophthalmol. 2012;154(3):549-59.

61. Wessel MM, et al. Ultra-wide-field angiography improves the detection and classification of diabetic retinopathy. Retina. 2012;32(4):785-91.

62. Silva PS, et al. Hemorrhage and/or microaneurysm severity and count in ultrawide field images and early treatment diabetic retinopathy study photography. Ophthalmology. 2017;124(7):970-6.

63. Silva PS, et al. Identification of diabetic retinopathy and ungradable image rate with ultrawide field imaging in a National Teleophthalmology Program. Ophthalmology. 2016;123(6):1360-7.

64. Hackenthal V. New scan for diabetic eye disease is better, but at a cost. In: Medscape ophthalmology. National Libraries of Medicine. 2016.

65. Tan ACS, et al. An overview of the clinical applications of optical coherence tomography angiography. Eye (Lond). 2018;32(2):262-86.

66. Spaide RF, et al. Optical coherence tomography angiography. Prog Retin Eye Res. 2018;64:1-55.

67. Krawitz BD, et al. Acircularity index and axis ratio of the foveal avascular zone in diabetic eyes and healthy controls measured by optical coherence tomography angiography. Vis Res. 2017;139:177-86.

68. Agemy SA, et al. Retinal vascular perfusion density mapping using optical coherence tomography angiography in normals and diabetic retinopathy patients. Retina. 2015;35(11):2353-63.

69. Dupas B, et al. Association between vessel density and visual acuity in patients with diabetic retinopathy and poorly controlled type 1 diabetes. JAMA Ophthalmol. 2018;136(7):721-8.

70. Ting DSW, et al. Optical coherence tomographic angiography in type 2 diabetes and diabetic retinopathy. JAMA Ophthalmol. 2017;135(4):306-12.

71. Samara WA, et al. Quantification of diabetic macular ischemia using optical coherence tomography angiography and its relationship with visual acuity. Ophthalmology. 2017;124(2):235-44.

72. Lord RK, et al. Novel uses of smartphones in ophthalmology. Ophthalmology. 2010;117(6):1274e3.

73. Tan GS, et al. Is routine pupil dilation safe among asian patients with diabetes? Investig Ophthalmol Vis Sci. 2009;50(9):4110-3.

74. Toy BC, et al. Smartphone-based dilated fundus photography and near visual acuity testing as inexpensive screening tools to detect referral warranted diabetic eye disease. Retina. 2016;36(5):1000-8.

75. Ryan ME, et al. Comparison among methods of retinopathy assessment (CAMRA) study: smartphone, nonmydriatic, and mydriatic photography. Ophthalmology. 2015;122(10):2038-43.

76. Russo A, et al. Comparison of smartphone ophthalmoscopy with slit-lamp biomicroscopy for grading diabetic retinopathy. Am J Ophthalmol. 2015;159(2):360-4.

77. Rajalakshmi R, et al. Validation of smartphone based retinal photography for diabetic retinopathy screening. PLoS One. 2015;10(9):e0138285.

78. Wadhwani $\mathrm{M}$, et al. Diabetic retinopathy screening programme utilising non-mydriatic fundus imaging in slum populations of New Delhi, India. Trop Med Int Health. 2018;23(4):405-14.

79. Sengupta $S$, et al. Screening for vision-threatening diabetic retinopathy in South India: comparing portable non-mydriatic and standard fundus cameras and clinical exam. Eye (Lond). 2018;32(2):375-83.

80. Sharma A. Emerging simplified retinal imaging. Dev Ophthalmol. 2017;60:56-62.

81. Matimba A, et al. Tele-ophthalmology: opportunities for improving diabetes eye care in resource- and specialist-limited Sub-Saharan African countries. J Telemed Telecare. 2016;22(5):311-6.

82. Rajalakshmi R, et al. Automated diabetic retinopathy detection in smartphone-based fundus photography using artificial intelligence. Eye (Lond). 2018;32(6):1138-44.

83. Pieczynski J, Grzybowski A. Review of diabetic retinopathy screening methods and programmes adopted in different parts of the world. Eur Ophthal Rev. 2015;9(1):49-55.

84. Tozer K, Woodward MA, Newman-Casey PA. Telemedicine and diabetic retinopathy: review of published screening programs. J Endocrinol Diabetes. 2015;2(4):1-10. 
85. Li HK, et al. Telehealth practice recommendations for diabetic retinopathy, second edition. Telemed J E-Health. 2011;17(10):814-37.

86. Zimmer-Galler I, Zeimer R. Results of implementation of the DigiScope for diabetic retinopathy assessment in the primary care environment. Telemed J E Health. 2006;12(2):89-98.

87. Cuadros J, Bresnick G. EyePACS: an adaptable telemedicine system for diabetic retinopathy screening. J Diabetes Sci Technol. 2009;3(3):509-16.

88. Massin P, et al. OPHDIAT: a telemedical network screening system for diabetic retinopathy in the Ilede-France. Diabetes Metab. 2008;34(3):227-34.

89. Schulze-Dobold C, et al. Ophdiat $((\mathrm{R}))$ : five-year experience of a telemedical screening programme for diabetic retinopathy in Paris and the surrounding area. Diabetes Metab. 2012;38(5):450-7.

90. Abramoff MD, Suttorp-Schulten MS. Web-based screening for diabetic retinopathy in a primary care population: the EyeCheck project. Telemed J E Health. 2005;11(6):668-74.

91. Sampson CJ, et al. Stratifying the NHS Diabetic Eye Screening Programme: into the unknown? Diabet Med. 2016;33(12):1612-4.
92. Sanchez CR, et al. Ocular telemedicine for diabetic retinopathy and the Joslin Vision Network. Semin Ophthalmol. 2010;25(5-6):218-24.

93. Aiello LM, et al. Joslin Vision Network Validation Study: pilot image stabilization phase. J Am Optom Assoc. 1998;69(11):699-710.

94. Lim MC, et al. Diabetic retinopathy in diabetics referred to a tertiary centre from a nationwide screening programme. Ann Acad Med Singap. 2008;37(9):753-9.

95. Nathoo $\mathrm{N}$, et al. The prevalence of diabetic retinopathy as identified by teleophthalmology in rural Alberta. Can J Ophthalmol. 2010;45(1):28-32.

96. $\mathrm{Ng} \mathrm{M}$, et al. Improving access to eye care: teleophthalmology in Alberta, Canada. J Diabetes Sci Technol. 2009;3(2):289-96.

97. Ting DS, Tay-Kearney ML, Kanagasingam Y. Light and portable novel device for diabetic retinopathy screening. Clin Exp Ophthalmol. 2012;40(1):e40-6.

98. Zhang W, et al. Screening for diabetic retinopathy using a portable, noncontact, nonmydriatic handheld retinal camera. J Diabetes Sci Technol. 2017;11(1):128-34. 